\title{
Research Article \\ Numerical Analysis of Flow Field in Generator End-Winding Region
}

\author{
Wei Tong ${ }^{1,2}$ \\ ${ }^{1}$ Kollmorgen Motors and Drives, Danaher Corporation, Radford, VA 24141, USA \\ ${ }^{2}$ Department of Mechanical Engineering, Virginia Polytechnic Institute and State University, Blacksburg, VA 24060, USA
}

Correspondence should be addressed to Wei Tong, tongzhuo24@yahoo.com

Received 16 October 2007; Accepted 19 February 2008

Recommended by Yoji Okita

Cooling in an end-winding region of a high-powered, large-sized generator still remains a challenge today because of a number of factors: a larger number of parts/components with irregular geometries, complexity in cooling flow paths, flow splitting and mixing, and interactions between rotor-induced rotating flows and nonrotating flows from stationary sections. One of the key challenges is to model cooling flows passing through armature bars, which are made up of bundles of strands of insulated copper wires and are bent oppositely to cross each other. This work succeeded in modeling a complex generator end-winding region with great efforts to simplify the model by treating the armature bar region as a porous medium. The flow and pressure fields at the end-winding region were investigated numerically using an axial symmetric computational fluid dynamics (CFD) model. Based on the analysis, the cooling flow rate at each flow branch (rotor-stator gap, rotor subslot, outside space block, and small ventilation holes to the heat exchanger) was determined, and the high-pressure gradient zones were identified. The CFD results have been successfully used to optimize the flow path configuration for improving the generator operation performance, and the control of the cooling flow, as well as minimizing windage losses and flow-introduced noises.

Copyright (c) 2008 Wei Tong. This is an open access article distributed under the Creative Commons Attribution License, which permits unrestricted use, distribution, and reproduction in any medium, provided the original work is properly cited.

\section{INTRODUCTION}

The power output rating of a high-powered, large-sized generator is often limited by the ability to provide additional current through the stator and rotor windings because of temperature limitations imposed on the electric conductor insulation. Therefore, effective cooling of stator and rotor windings contributes directly to the output capability of the generator. This is especially true in the generator endwinding region where the cooling flow path configuration is considerably complicated. As prevailing market trends require higher efficiency, higher reliability, lower cost, and higher-power density generators, cooling the end-winding region has become a limiting factor for the generator power output rating.

A generator cooling system is used to maintain the stator and rotor windings to allowable operating temperatures. During normal generator operation, heat is generated in a generator due primarily to windage and friction, electric current flow, and time-varying magnetic fields in magnetic structures. Friction heating occurs as the rotor spins at high speed in the generator. Similarly, heating also occurs as current flows through the rotor and stator coils, as these coils rotate relative to one another in the magnetic fields of the generator. Losses in the magnetic circuit occur as the magnetic fields change with time in permeable materials such as in the stator core and the rotor poles of a synchronous generator [1]. Generators are conventionally equipped with cooling systems to transfer heat from the generator with a cooling medium such as air or hydrogen gas.

According to the cooling flow configuration, cooling systems can be primarily categorized into two types. A most commonly used in the power industry is the forward flow cooling system in which cooling gas is provided from ventilation fans and passed through parallel paths to both the stator and the rotor simultaneously. Another type is the reverse flow cooling systems that have been developed since the 1980s. The main advantage of using reverse flow is a characteristic high cooling efficiency, and an uprating capability of the rotor end turns. With the reverse flow configuration, the cooling gas flows directly from the coolers to the rotor without passing through a fan, and the cooling 
gas absorbs no heat other than a portion of the core losses in the yoke. Hence, it offers cooling gas at lower temperatures not possible from other known ventilation arrangements. However, reverse flow ventilation also results in a longer machine and somewhat greater complexity in the generator end region [2].

A typical forward flow cooling system is shown in Figure 1. Since the generator is symmetric to its horizontal and vertical centerlines, only a quarter of the generator needs to be investigated. It can be observed from Figure 1 that the flow configuration employs an axial ventilation fan at each end of the rotor that supplies the cooling flow. The cooling gas leaving the ventilating fan splits into four flow branches: the rotor-stator gap, the rotor subslot, outside space block, and ventilating holes to the heat exchanger. As the cooling gas leaves the fan and approaches the rotor, the rotating surfaces act to accelerate the gas to rotor speed. This helps pump the cooling gas passing through the armature bars as well as the gap between the gas shield and armature bars. The cooling flow splits at the front of the centering ring to enter the rotor-subslot and the rotor-stator gap, respectively. The cooling gas in the rotor subslot cools the rotor core by flowing through the radial rotor cooling ducts and mixes with the cooling gas in the rotor-stator gap. Then, the mixed gas flows through the stator core in a radial outward direction. Since the hot rotor gas significantly affects the temperature of the stator core, the cooling gas distribution through both the rotor and stator must be carefully designed. In addition, to best cool the ends of the armature bars near the series loop caps, the gap formed between the edges of armature bars and the tip of the gas shield must be carefully determined for controlling the cooling flow rate through it.

The end-winding region is located at each end of the generator. There are a large number of parts and components in this region including a ventilation fan that serves to force cold gas into the generator, a gas shield defining a passage for the entered cold gas, armature bars, a retaining ring, a centering ring, rotor end-windings, power connection rings, and a stator flange. As a result, the flow field in this region is considerably complex. For large-sized, highpowered generators, the cooling flow at the end-winding region has drawn special attention because it may result in locally hot spots on the end-winding bars and large ventilating windage losses. In fact, how well the armature winding of a generator is cooled has a significant influence on the overall size of a synchronous generator [3].

The objective of the present work is to investigate the flow and pressure fields at the generator end-winding region. Results of the investigation have been successfully used in design optimization and design integration for hydrogencooled, high-efficiency generators.

\section{MATHEMATICAL FORMULATION}

The cooling system shown in Figure 1 is different from most conventional generator cooling systems by applying a oncethough cooling scheme. With this scheme, the cooling gas flows through the cooling slots of the rotor and stator. Then, the exhausted cooling gas from the rotor will mix with the stator cooling gas to cool the stator together. In this way, the cooling gas is circulated in a close loop within the generator and is cooled by gas-to-water heat exchanges. Since the oncethrough cooling scheme requires a less cooling flow rate compared with other cooling schemes, it leads to a simplified frame construction.

Hydrogen is utilized as the cooling media in the present work due to its superior thermophysical properties (e.g., high specific heat and thermal conductivity, low density, etc.). The higher effectiveness of hydrogen as a cooling media allows a 20-30\% size decrease over an air-cooled machine of a similar rating.

As the generator operation conditions are specified, the required cooling gas flow rate is primarily determined by the power output, temperature limits at the rotor and stator windings, and total generator losses. In the current design, the total volumetric flow rate $\dot{Q}$ at each cooling fan is approximately 34500 gallon per minute (GPM). The thermal properties of $98 \%$ pure hydrogen are presented in Appendix A.

\subsection{Governing equations}

The advanced renormalization group (RNG) $k-\varepsilon$ turbulent model was applied in this analysis, since the model provides an option to account for the effects of rotation by modifying the turbulent viscosity appropriately. The RNG procedure employs dynamic scaling and invariance together with iterated perturbation methods, allowing evaluating transport coefficients and transport equations for the largescale modes. The RNG model has been derived from the instantaneous Navier-Stokes equations and has shown to be especially suitable for solving rotating or swirl flow problems [4-6].

It is assumed that all thermal properties of the cooling flow are constant. Hence, the steady state, axisymmetric, incompressible, turbulent flow is governed by the continuity, momentum, and $k-\varepsilon$ turbulence model equations in tensor notation as follows:

$$
\begin{gathered}
u_{j, j}=0, \\
\rho\left(u_{j} u_{i, j}\right)=-p_{, i}+\mu_{\mathrm{eff}}\left(u_{i, j}+u_{j, i}\right)_{, j}, \\
\rho\left(u_{j} k_{, j}\right)=\mu_{t} S^{2}-\rho \varepsilon+k_{, j}\left(\alpha_{k} \mu_{\mathrm{eff}}\right)_{, j}, \\
\rho\left(u_{j} \varepsilon_{, j}\right)=C_{1 \varepsilon} \frac{\varepsilon}{k} \mu_{t} S^{2}-C_{2 \varepsilon} \frac{\varepsilon^{2}}{k}+\varepsilon_{, j}\left(\alpha_{\varepsilon} \mu_{\mathrm{eff}}\right)_{, j}-\mathfrak{R},
\end{gathered}
$$

where $S^{2}=2 S_{i j} S_{i j}$ is the modules of the rate-of-strain tensor, $\alpha_{k}$ and $\alpha_{\varepsilon}$ are the inverse Prandtl number for $k$ and $\varepsilon$, respectively, $\mu_{t}$ and $\mu_{\text {eff }}$ are the turbulent and effective viscosity, respectively,

$$
\begin{aligned}
\mu_{t} & =\rho C_{\mu} \frac{k^{2}}{\varepsilon}, \\
\mu_{\mathrm{eff}} & =\mu\left(\sqrt{\frac{\rho C_{\mu}}{\mu}} \frac{k}{\varepsilon^{1 / 2}}\right)^{2} .
\end{aligned}
$$




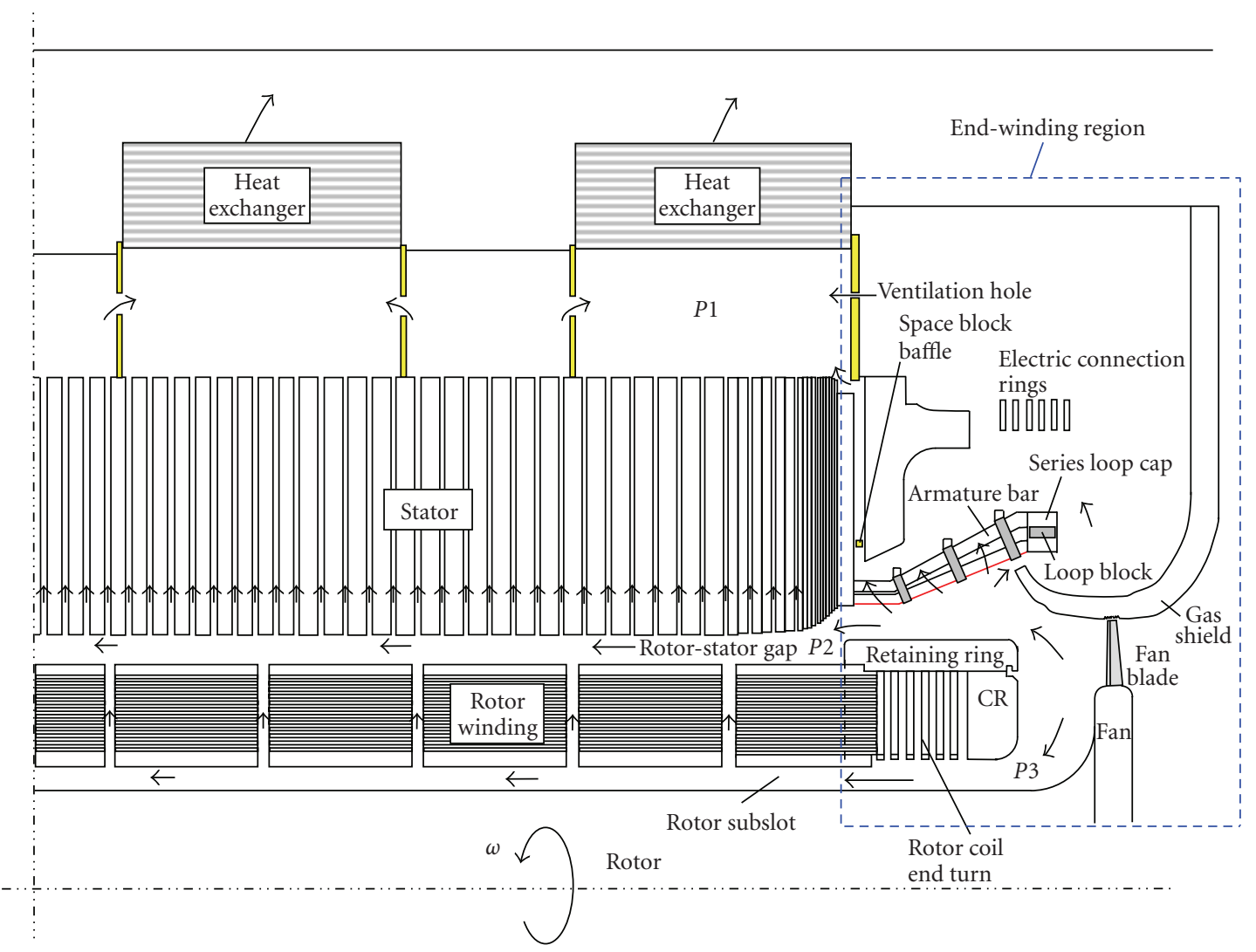

FIGURE 1: Schematic diagram of the generator cooling system and end-winding region.

The last term in (4) is the rate-of-strain term defined as

$$
\Re=\frac{C_{\mu} \eta^{3}\left(1-\eta / \eta_{o}\right)}{1+\zeta \eta^{3}} \frac{\varepsilon^{2}}{k},
$$

where $\eta \equiv S k / \varepsilon, \eta_{o} \approx 4.38, \zeta=0.012$. Note that the model constants $C_{1 \varepsilon}$ and $C_{2 \varepsilon}$ are derived from the RNG theory and $C_{\mu}$ is determined experimentally. The constant values are $C_{\mu}=0.0845, C_{1 \varepsilon}=1.42, C_{2 \varepsilon}=1.68, \alpha_{k}=\alpha_{\varepsilon}=1.393$.

\subsection{Boundary conditions}

The boundary conditions include the flow inlet conditions at the cooling fan exit, three pressure boundary conditions at the flow exits $\left(p_{1}, p_{2}\right.$, and $p_{3}$ in Figure 1$)$, the rotor rotating speed, and no-slip boundaries on all surfaces of the stationary components. The flow inlet conditions were obtained from a separate CFD model to present the velocity profiles at the cooling fan exit (Appendix B). The pressure boundaries, locating at the middle of the ventilation space to the first heat exchanger $\left(p_{1}\right)$, the rotor-stator gap entrance $\left(p_{2}\right)$, and the rotor subslot entrance $\left(p_{3}\right)$, were obtained directly from a generator design export system which uses 1D networks to determine the required flow rate at each cooling branch. For a $60 \mathrm{~Hz}$ generator, the rotor rotating speed is $3600 \mathrm{rpm}(377 \mathrm{rad} / \mathrm{s})$.

\subsection{Numerical methodology}

A commercial CFD code FLUENT/UNS [7] was used to simulate the turbulent flow at the generator end-winding region to provide an insight into the details of the flow features over the region. This code has been successfully used in cooling analysis for different generator applications [810].

The overall quality of grids is of primary importance in predicting flow distributions in this complex computational domain. In this analysis, unstructured triangular grids were employed. In order to improve the accuracy of the numerical results without significantly decreasing efficiency and to optimize the utilization of the available computational resources, the local grid refinement technique was employed at the solid surfaces and the regions with high-pressure gradients. Considering this strategy during the mesh generation, a reasonable compromise between high spatial resolution and efficiency, for example, CPU time and memory requirement must be made. In the near-wall region, nonequilibrium wall functions were applied in the analysis.

In order to achieve more stable and accurate results, the rotational speed was initially set at a very low value $(\omega=$ $60 \mathrm{rad} / \mathrm{s}$ ) and increased by small increments until reaching the normal operation rotating speed $\omega=377 \mathrm{rad} / \mathrm{s}$. The underrelaxation parameter was set at 0.3 for pressure, 0.60 0.90 for momentum, $k$ and $\varepsilon$. Second-order discretization algorithms were used to reduce the amount of artificial 


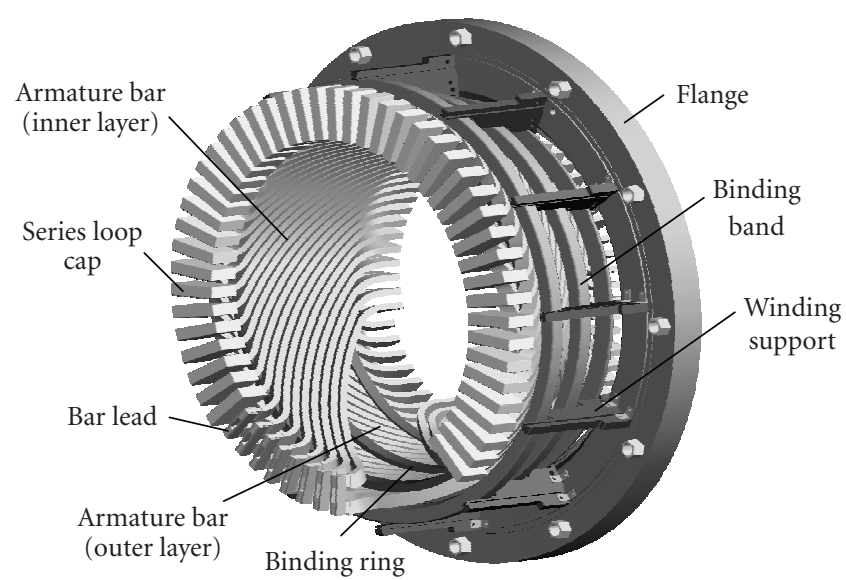

FIGURE 2: Structure of the stator end windings.

dissipation introduced by the numerical computation. The effects of changing underrelaxation factors for different variables, different convective schemes, and grid sizes on the solution convergence for turbulent flows were addressed in detail by Barron and Neyshabouri [11].

In this analysis, convergence was assumed to be satisfied when the maximum sum of the normalized residuals in all equations was reduced less than $10^{-4}$. All computations were executed on a Hewlett Packard Workstation 785/C3600.

\subsection{Porous media regions}

The stator winding coils are made up of bundles of strands of insulated copper wires and embedded in the slots of the stator core. At the end-winding region, the stator coils at the inner and outer layers are bent oppositely to cross each other (Figure 2). The coil ends are brazed together to form bar leads for providing electric current paths. In order to protect the bar leads, each lead is covered with a series loop cap. The armature bars are supported by a support system, including the stator winding supports and binding bands at the outward of the stator end-windings, and the binding rings between two winding layers.

The structure of the stator end windings is illustrated in Figure 3. The armature bars are bonded with the binding bands (not shown) and binding rings using fiberglass tape tie cords. Series loop cap blocks are used between the series loop caps to provide mechanical supports to the armature bars. According to the flow patterns, nine flow zones are identified on the armature bars with different flow characteristics.

As discussed above, the cooling flows passing though the armature bars are considerably complex. An effective way to simplify the analysis is to treat the armature bars as a porous media, that is, the flow passing through the bars (which has only a fraction of the flow area open) is equivalent as the flow passing through a porous media (which has a $100 \%$ open flow area) with an identical mass flow rate and pressure drop [12], that is,

$$
\begin{aligned}
\Delta p_{a} & =\Delta p_{p}, \\
\dot{m}_{a} & =\dot{m}_{p} .
\end{aligned}
$$

Introducing the loss coefficient $K$, which is defined as

$$
K=\frac{\Delta p}{(1 / 2) \rho u^{2}}
$$

it follows that

$$
\begin{aligned}
& \Delta p_{a}=K_{a}\left(\frac{1}{2} \rho u_{a}^{2}\right), \\
& \Delta p_{p}=K_{p}\left(\frac{1}{2} \rho u_{p}^{2}\right) .
\end{aligned}
$$

Applying (10) into (7), it yields

$$
K_{a} \frac{\rho V_{a}^{2}}{2}=K_{p} \frac{\rho V_{p}^{2}}{2}
$$

that is,

$$
K_{p}=K_{a}\left(\frac{V_{a}}{V_{p}}\right)^{2} .
$$

In calculating porous media flows, an important parameter $\eta$ is introduced and defined as the ratio of the actual open area to the total flow area (100\% open),

$$
\eta=\frac{A_{a}}{A_{p}} .
$$

Equation (8) can be rewritten as

$$
\rho A_{a} V_{a}=\rho A_{p} V_{p} .
$$

Therefore, the relationship between the velocity ratio $V_{a} / V_{p}$ and $\eta$ can be determined as

$$
\frac{V_{a}}{V_{p}}=\frac{A_{p}}{A_{a}}=\frac{1}{\eta}
$$

Substituting (15) into (12), it yields

$$
K_{p}=\frac{K_{a}}{\eta^{2}}
$$

Thus, the porous media inertial resistance factor $\xi$, defined as the pressure loss factor per unit length, can be determined as

$$
\xi=\frac{K_{p}}{\Delta L},
$$

where $\Delta L$ is the length through the media in the flow direction.

Thus, with (13), (16), and (17) the flow characteristics can be obtained at each porous flow zone of the armature bars (see Figure 3). By integrating the porous media parameters into the CFD model, the velocity and pressure fields at the end-winding region are determined. 


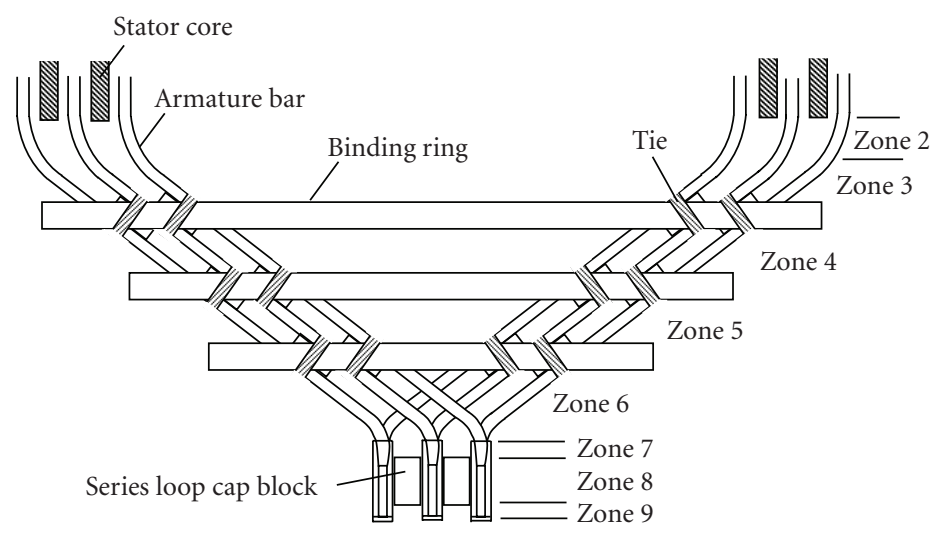

FIGURE 3: Layout of armature bars, binding bands, and flow zones (only armature bar outer layer presented).

\section{NUMERICAL RESULTS}

\subsection{Flow and pressure fields}

At the axial flow entrance from the fan discharge region, the cooling flow passes through the annular restriction between the rotor retaining ring and the end of the stator core. Figure 4 illustrates typical velocity fields at the end-winding region. Like an impinging jet, the axial cooling flow splits in two branches when it hits the retaining ring and center ring: one turns up toward the end-winding bars and another turns two 90 degrees to get into the rotor subslot. Due to the high flow resistance of the end-winding bars, while a small portion of the cooling flow gets through these bars, the main flow splits again in opposite directions along the edge of the end-winding bars. The main part of the gas flows towards the stator-rotor gap and another to the series loop caps. As shown in Figure 4, the gap between the armature bars and the gas shield is used to control the flow rate for stator bar lead cooling. However, due to the existence of the solid series loop block, the cooling flow could not reach the top part of the series loop, leaving the zone uncooled. In addition, it has also weakened the cooling of connection rings.

The static pressure contours at the end-winding region are presented in Figure 5. It can be seen that the highpressure gradient, which is associated with the high-pressure drop, occurs at the stator-rotor gap entrance, the rotor subslot entrance, the outboard of the retaining ring, and the flow gap between the gas shield and the armature bars. These high-pressure gradients can result in large windage losses.

Figure 6 presents the dynamic pressure contours at the end-winding region. Because dynamic pressure is proportional to $\mathbf{u}^{2}$, its distribution is similar to that in Figure 4. The highest dynamic pressure occurs at the fan flow entrance. It clearly shows that the uncooled zone appearing at the top portion of the series loop cap. As the flow passes the space block baffle, it produces a large pressure drop.

\subsection{Flow rate distribution}

One of the main objectives of this work is to find the cooling flow distribution through all four flow branches, including:

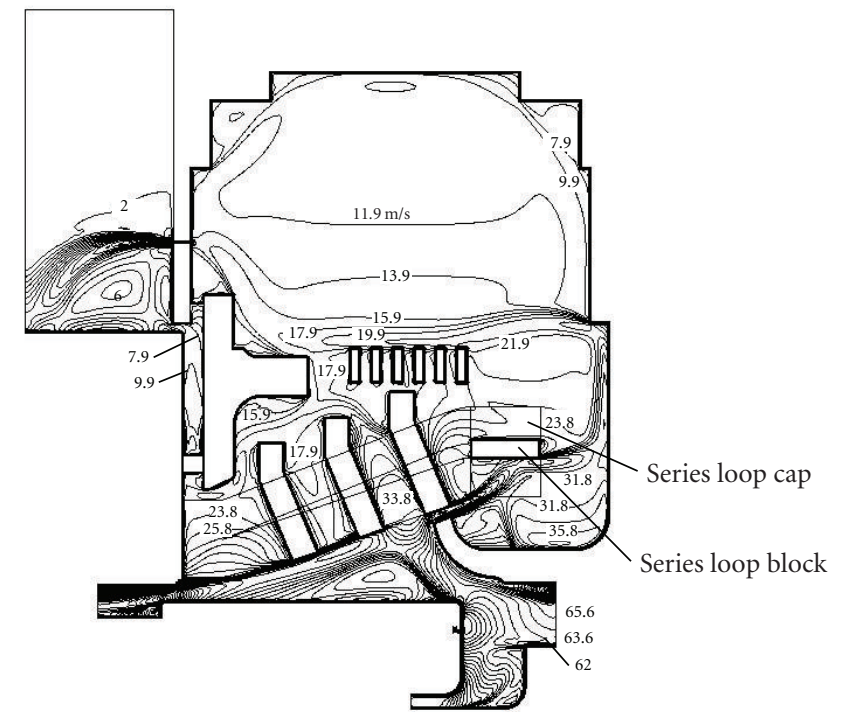

FIgURE 4: Velocity contours in the generator end-winding region.

TABLe 1: Comparison of flow distribution between 1D network model and CFD model.

\begin{tabular}{llc}
\hline Flow branch & $\begin{array}{l}\text { 1D network } \\
\text { model (\%) }\end{array}$ & CFD model (\%) \\
\hline Ventilation hole to cooler & 9.71 & 10.33 \\
Outside space block & 5.67 & 7.55 \\
Stator-rotor air gap & 56.45 & 54.94 \\
Rotor subslot & 28.18 & 27.18 \\
\hline
\end{tabular}

the flow passing through the rotor-stator gap, rotor subslot, ventilating holes to the cooler, and outside space block. The comparison of the flow distribution between the onedimensional network model and the CFD model is given in Table 1. It can be seen that except the flow through outside space block the differences between two are less than $\pm 6.5 \%$. Because the flow rate through the outside space block takes a small portion of the total flow rate (6-7\%), it has little influence on entire generator cooling. 


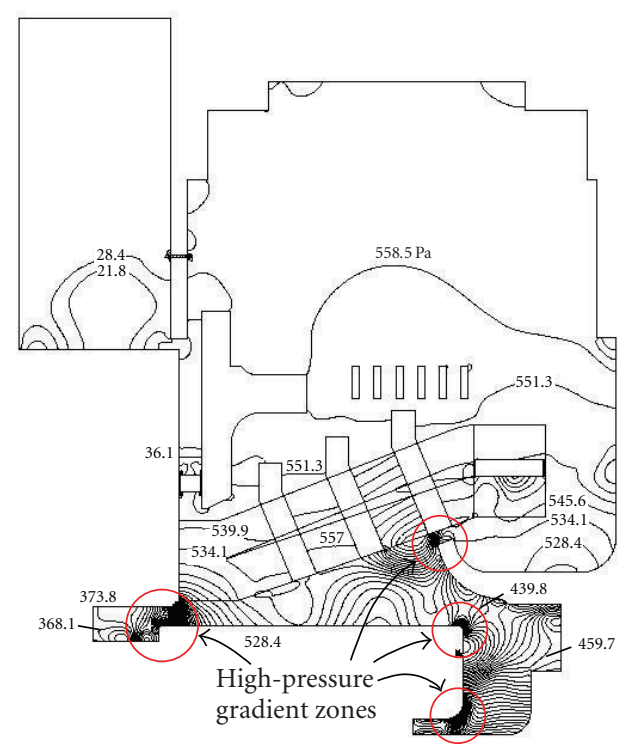

FIGURE 5: Static pressure contours at the end-winding region with circled high-pressure gradient.

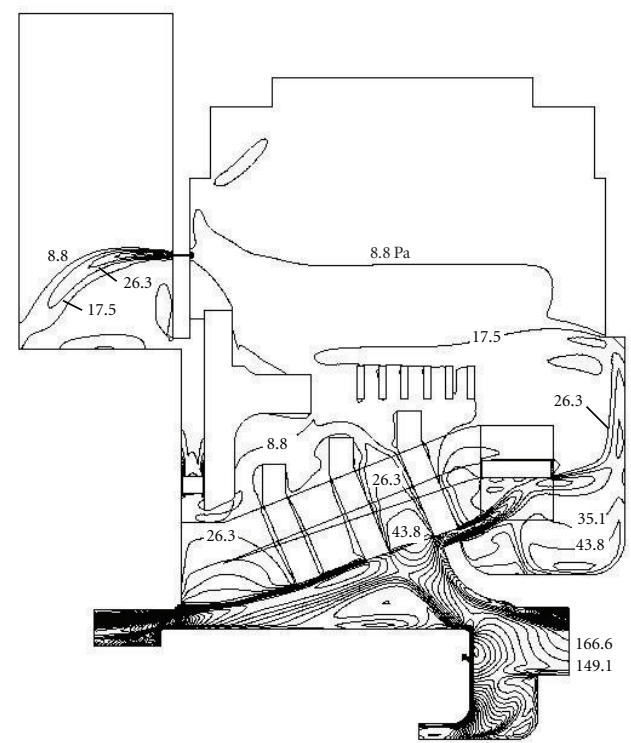

FIGURE 6: Dynamic pressure contours at the end-winding region.

\subsection{Velocity profiles across the bottom armature bar edges}

Figures $7(\mathrm{a})-7(\mathrm{c})$ present velocity component profiles along the bottom edges of the armature bars, with the starting point at the root of the armature bars (see the red line in Figure 1). Figure 7(a) demonstrates the axial velocity distribution $\left(u_{x}\right)$, which shows that the minimum (negative) axial velocity occurs near the bar root and the maximum (positive) at the gas gap between the gas shield and the bar tie (throttling flow). As discussed previously, this is because that the flow resistance of the bar is rather high, as the cooling gas hits the armature bars, it splits into opposite directions

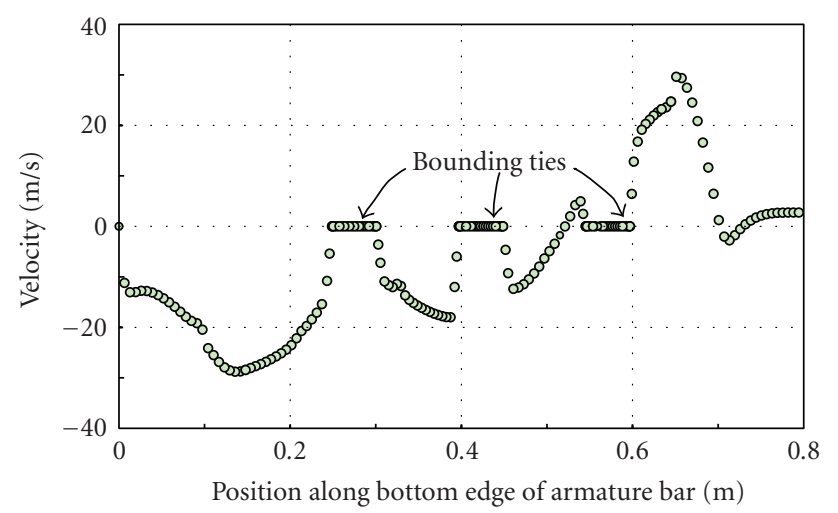

(a) Axial velocity profile along the bottom edge of the armature bars

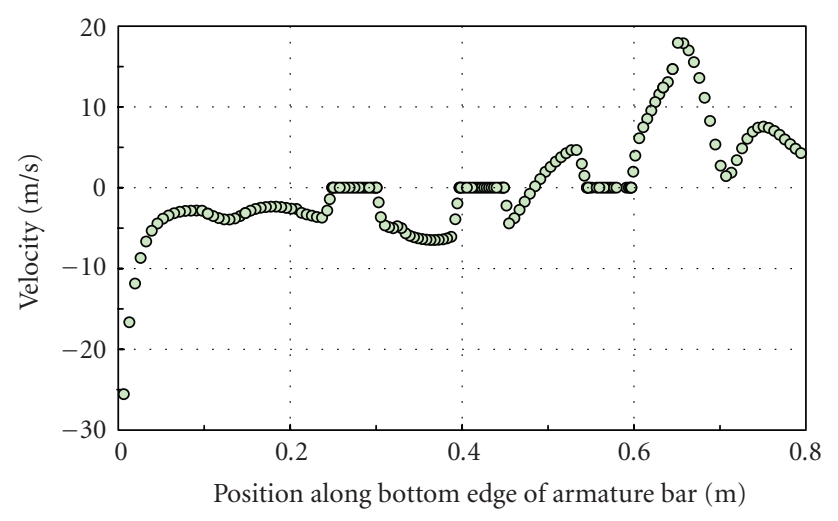

(b) Radial velocity profile along the bottom edge of the armature bars

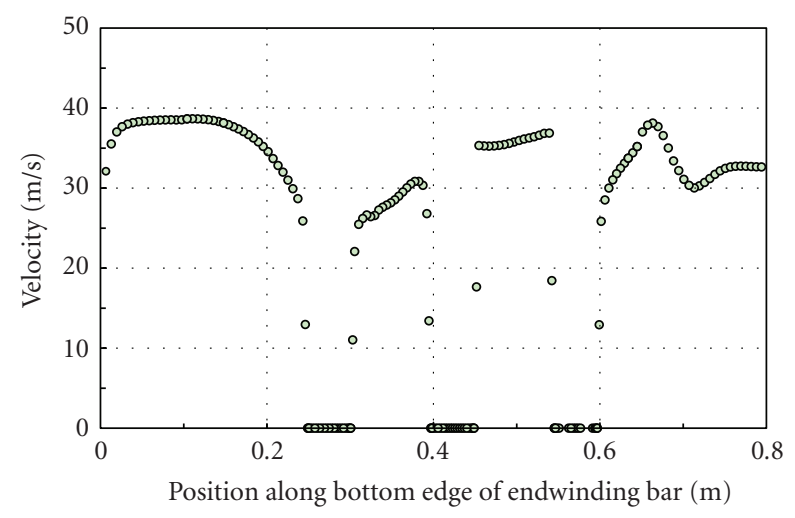

(c) Swirl velocity profile along the bottom edge of the armature bars

Figure 7

along the bar edges. The radial velocity distribution $\left(u_{r}\right)$ is displaced in Figure 7(b). At the bar root, which is near the rotor-stator gap entrance, the radial flow is negative due to the suction effect of the gas flow through the annular rotorstator gap. The radial velocity turns to the positive after the second bar tie. The swirl velocity $u_{\theta}$ at the bottom edge of the armature bars is resulted from the rotor rotation. Unlike to the axial and radial velocities, the swirl velocity is more uniform; no negative values are observed (Figure 7(c)). In all cases, the velocity components vanish at the locations of the bar ties. 


\section{DESIGN OPTIMIZATION}

Windage is the term generally used to denote the loss due to fluid drag on a rotating body. For rotors at high peripheral speeds, air friction (i.e., windage) on the rotor surfaces is significantly large and hence the reduction of windage losses is highly desired with the growing development of highspeed turbomachinery.

Windage losses in a generator are critical to the generator performance and operation reliability. Among various windage losses, the ventilation loss is a significant contributor to the total loss. The ventilation losses occur at backwardand forward-facing steps, sharp turns, sudden contractions and expansions, and the torturous paths. In order to enhance generator efficiency, such losses must be minimized.

\subsection{Spline retaining ring}

It can be observed from Figure 5 that a primary pressure drop occurs at the rotor-stator gap entrance due to the sudden change in the flow area and the torturous ventilating flow path. At the rotor-stator gap entrance, a bottleneck is formed between the retaining ring inboard end and the end-core taper on the stator. As cooling gas passes through the gap entrance, the significant flow acceleration causes a large local pressure drop that is only partially recovered downstream. By using spline retaining rings, windage losses can be remarkably reduced and the effectiveness of the cooling system can be enhanced.

A spline retaining ring has a modified outer profile at the axially inboard end portion, from a flat cylindrical surface to an aerodynamically curved spline surface. Hence, the effective flow cross-sectional area increases, and the drag force against the axial cooling flow decreases [13]. In fact, with the spline retaining ring, approximately $60 \%$ of the windage loss across the stator-rotor gap entrance can be avoided, resulting in a whole generator efficiency increase of about $0.01 \%$. The advantages of using the spline retaining rings are (a) decreasing the pressure drop across the statorrotor gap entrance; (b) reducing the drag force against the axial cooling flow at the stator-rotor gap entrance; (c) enhancing the cooling capability and temperature uniformity; (d) improving cooling flow fluidity; and (e) reducing flow-induced noises.

Figure 8(a) illustrates the velocity vectors at the statorrotor gap entrance with a conventional retaining ring. The cooling gas is forced to flow into the gap. From Figure 8(a), it can be seen that a large flow recirculation is formed at the front of the retaining ring inboard end, leading to a large windage loss.

Figure 8(b) illustrates the velocity vectors at the gap entrance region with the spline retaining ring. Cooling gas is shown to flow smoothly along the retaining ring surface. Thus, there is no flow recirculation occurring at the retaining ring inboard end. In addition, due to the enlarged effective flow cross-sectional area at the rotor-stator gap entrance, the static pressure at the gap entrance becomes higher, helping the cooling gas filling into the stator slots.

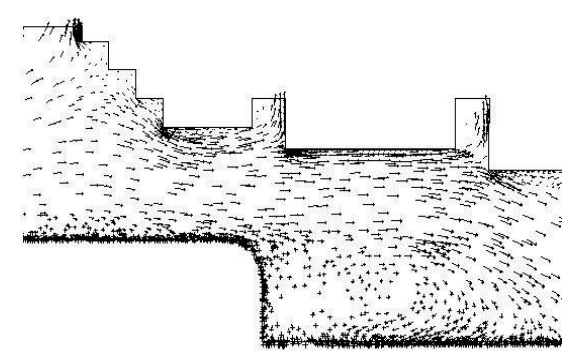

(a)

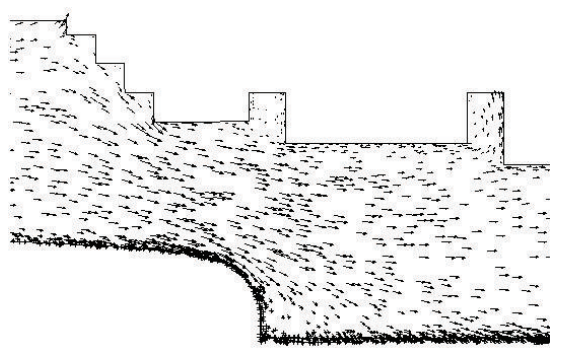

(b)

Figure 8: Flow fields at the rotor-stator gap entrance with (a) regular retaining ring, (b) spline retaining ring.

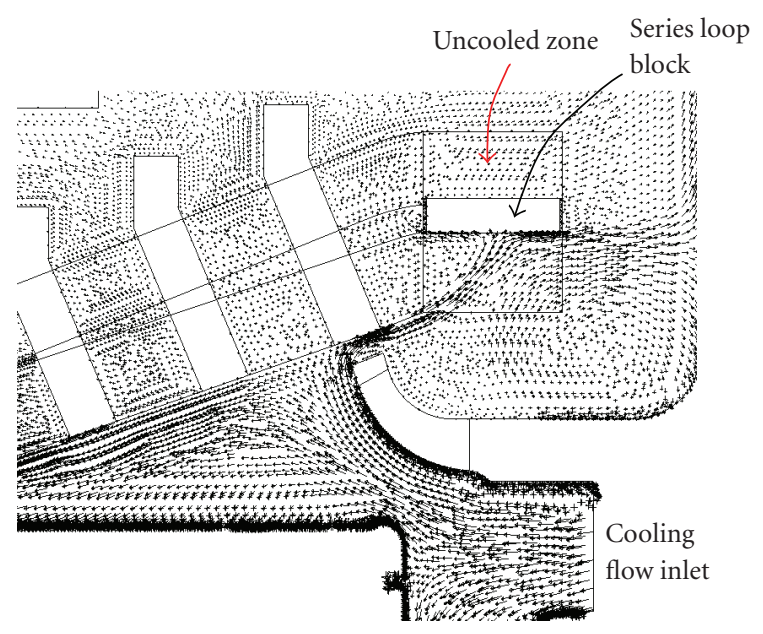

FIGURE 9: Uncooled zone appearing above the series loop block.

\subsection{Series loop block}

The end-winding support system restrains the movement of the sections of the armature bars that extend outside the core. In the support system, series loop blocks are used to reduce the operational deflections of the series loops at resonance and to withstand electromagnetic forces acting on the series loops. However, it can be seen in Figure 9 that as the solid loop block is installed with the series loop cap, the flow path to the outward part of the series loop cap is completely blocked, leading to hot spots occurring in this uncooled zone.

The optimizing design is proposed to improve series loop cooling. As shown in Figure 10, a ventilating groove is machined at each side of the block to allow cooling gas 


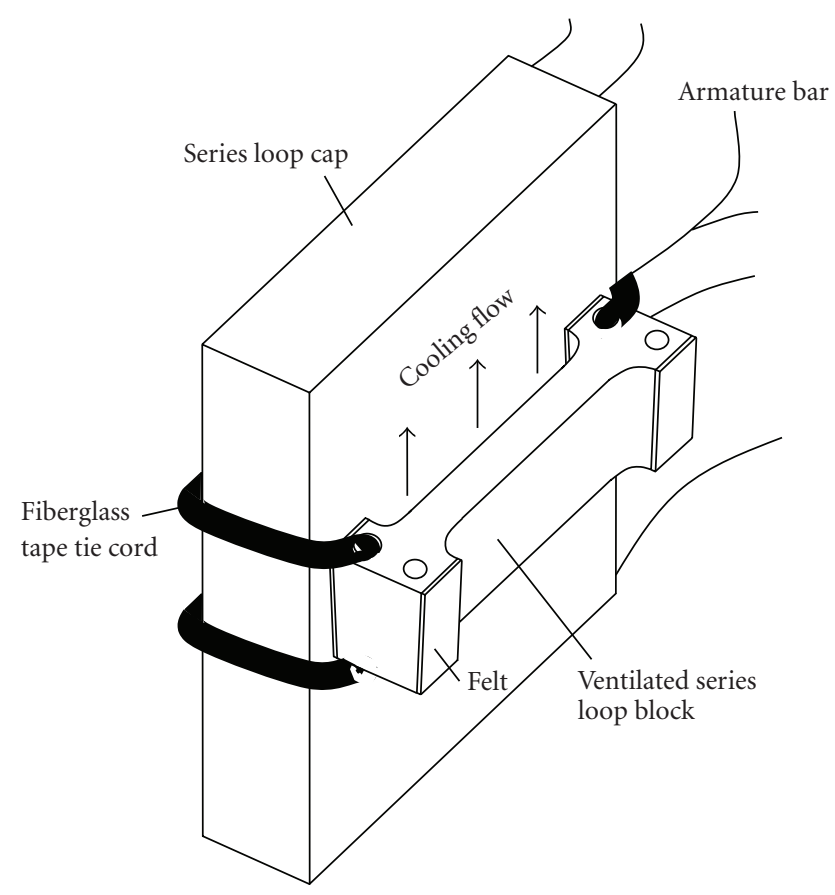

FIGURE 10: Assembly of ventilated series loop block with series loop cap.

passing through it. One or two tie holes at the block ends are used to bond the block with the adjacent series loop caps. To better fit the gap between two adjacent series loop caps, the block contacting surfaces are made slightly nonparallel. A layer of felt is inserted between the block and series loop cap. With this design change, hot spots at the series loop blocks can be effectively eliminated.

In addition to improved cooling efficiency, another advantage of the ventilated block over the solid block is that it can be custom fitted to the gap between two adjacent series loop caps. This is because the contact area with the adjoining cap of the ventilated block is much smaller than that of the solid block. Hence, the smaller contact area permits the surface to be grounded for custom fitting to irregular gaps between adjacent caps, thus obtaining a tighter fit and improving performance. The conventional solid blocking does not easily accommodate large variations in the gap dimension and relies on build up of felt to be effective [14].

\subsection{Outer space block baffle}

A number of baffles in the outside space block are used to control cooling gas flow rates through the space block flow channels. However, the conventional L-shaped baffles (see Figure 11 for the prior art) have several disadvantages. First, this type of baffles is nonadjustable. As the baffle dimension is specified, the flow rate through the flow channel is fixed. Thus, one baffle dimension can only satisfy a specific cooling requirement. Second, as the cooling gas flows across an Lshaped baffle, it generates a flow recirculation due to the sudden expansion of the flow area and thus results in a highpressure drop, that is, a high windage loss.

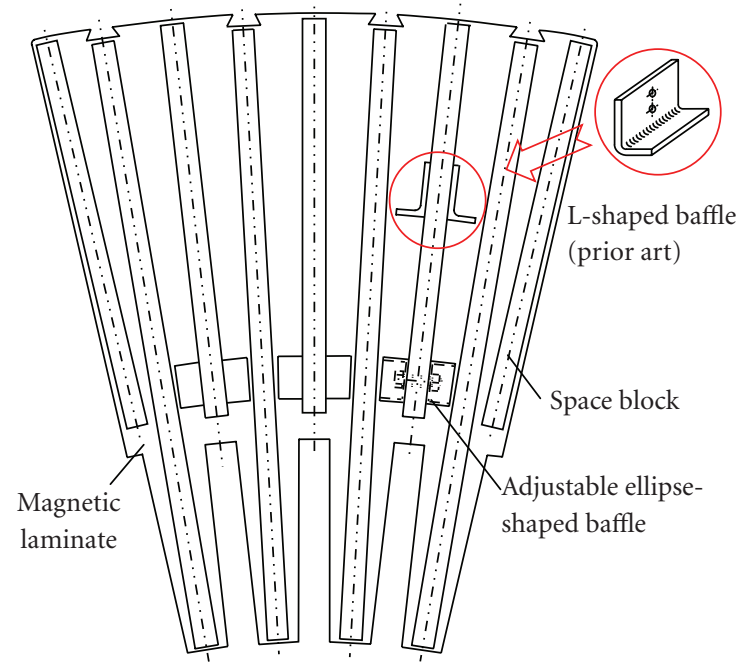

FIGURE 11: Assembly of adjustable ellipse-shaped baffles on outside space block.
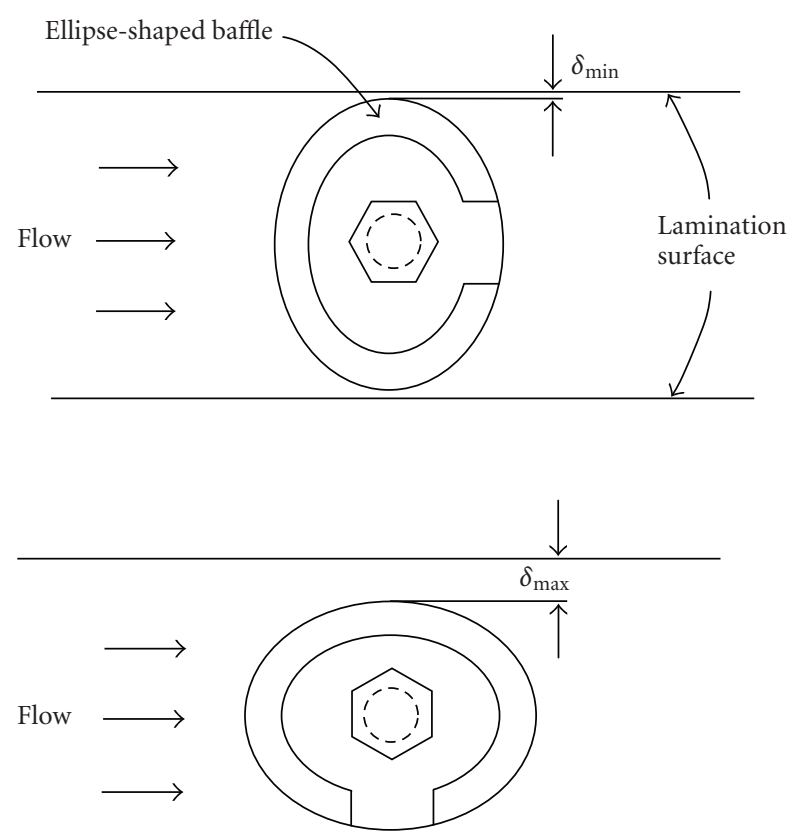

Figure 12: Adjustment of cooling flow with an ellipse-shaped baffle.

To solve these problems, new-designed space block baffles are presented, as shown in Figure 11. The adjustable baffle is in an ellipse shape and mounted on the block with one bolt at its center (Figure 12). In such a way, the flow gap $\delta$ is formed between the baffle and the block surface. As the long axis of the ellipse is perpendicular to the block, the flow gap becomes smallest (i.e., $\delta=\delta_{\min }$ ). As it turns 90 degree to be parallel to the block, $\delta=\delta_{\max }$. Thus, the flow gap is adjustable by setting the baffle location relative to the block. By selecting the appropriate ellipse long and short axes, the baffles can control the cooling flow rate in a wide range and, 
TABle 2

\begin{tabular}{ccccc}
\hline$T\left({ }^{\circ} \mathrm{C}\right)$ & $\mu(\mathrm{kg} / \mathrm{m}-\mathrm{s})$ & $c_{p}(\mathrm{~J} / \mathrm{kg} \mathrm{K})$ & $\lambda(\mathrm{W} / \mathrm{m} \mathrm{K})$ & $\rho\left(\mathrm{kg} / \mathrm{m}^{3}\right)$ \\
\hline 40 & $9.853 \mathrm{E}-06$ & 11309 & 0.181 & 0.3027 \\
50 & $1.006 \mathrm{E}-05$ & 11323 & 0.186 & - \\
60 & $1.027 \mathrm{E}-05$ & 11336 & 0.190 & 0.2846 \\
70 & $1.048 \mathrm{E}-05$ & 11347 & 0.194 & - \\
80 & $1.060 \mathrm{E}-05$ & 11358 & 0.199 & 0.2684 \\
90 & $1.089 \mathrm{E}-05$ & 11368 & 0.203 & - \\
100 & $1.109 \mathrm{E}-05$ & 11377 & 0.207 & 0.2540 \\
110 & $1.129 \mathrm{E}-05$ & 11386 & 0.211 & - \\
120 & $1.149 \mathrm{E}-05$ & 11394 & 0.215 & 0.2411 \\
130 & $1.169 \mathrm{E}-05$ & 11401 & 0.219 & - \\
140 & $1.189 \mathrm{E}-05$ & 11408 & 0.224 & 0.2294 \\
\hline
\end{tabular}

as a consequence, can satisfy various cooling requirements. Moreover, with the new designed baffles, the flow rate at each flow channel of the space block can be controlled individually to gain the best cooling effect [15].

\section{CONCLUSIONS}

A numerical investigation of the velocity and pressure fields at the end-winding region of a hydrogen-cooled generator was performed under generator normal operation conditions. A porous media model was developed to simulate cooling flows passing through the armature bars with different loss coefficient $K$ and inertial resistance factor $\xi$ at each porous flow zone of the armature bars. High-pressure gradients have been found to occur at the stator-rotor gap entrance, the rotor subslot entrance, the outboard of the retaining ring, and the flow gap between the gas shield and the armature bars. The predicted velocity field also reveals that with the original design the uncooled zones occur at the top portion of the series loop caps.

Based on the numerical results, the cooling flow path configuration has been optimized for improving the generator operation performance and the control of the cooling flow, including (a) using the spline retaining rings to replace the conventional cylindrical ones, (b) redesigning the series loop block with ventilating grooves at the contacting sides with serious loop caps, and (c) using the ellipseshaped baffles to replace antiquated L-shaped baffles for better controlling the ventilating flows through the space block flow channels. These design changes have substantially enhanced the generator operation performance and reliability. All of the above innovations have led to awarded U.S. patents.

\section{APPENDICES}

\section{A. THERMAL PROPERTIES OF COOLING GAS}

The analyses were run with a $98 \%$ pure hydrogen and $2 \%$ air mixture at $30 \mathrm{psig}(206.8 \mathrm{kPa})$. The thermophysical properties are listed as in Table 2.

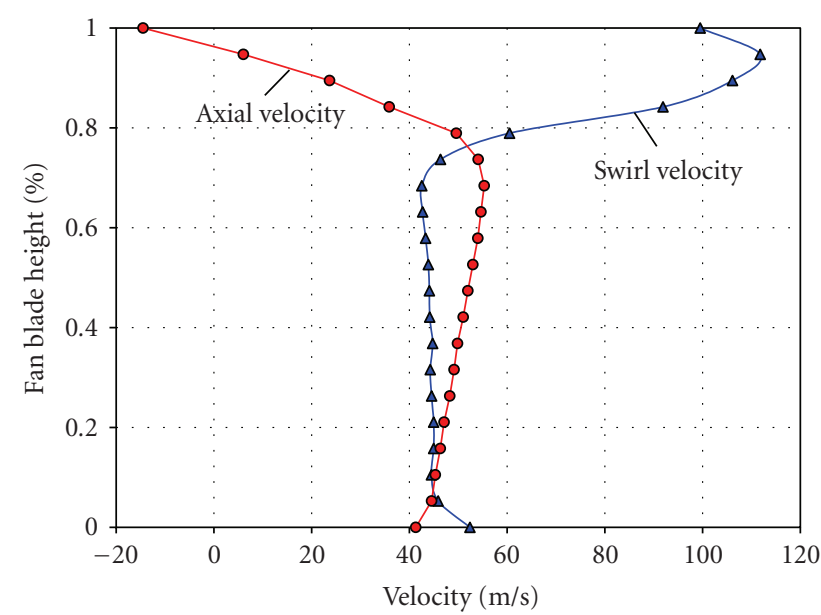

Figure 13: Velocity distributions alnog the fan blade height.

\section{B. VELOCITY PROFILES AT THE FAN EXIT}

The ventilation fan used in the present design has 24 blades with the blade angle of $18^{\circ}$. The velocity field at the fan exit was obtained from a separate CFD model. The axial and swirl velocity profiles are presented in Figure 13.

\section{NOMENCLATURE}

$\begin{array}{ll}A: & \text { Area } \\ C_{1 \varepsilon}, C_{2 \varepsilon}, C_{\mu}: & \text { Constants in the turbulence model } \\ c_{p}: & \text { Specific heat } \\ K: & \text { Loss coefficient } \\ k: & \text { Turbulence kinetic energy } \\ \dot{m}: & \text { Mass flow rate } \\ p: & \text { Pressure } \\ \dot{Q}: & \text { Volumetric flow rate } \\ T: & \text { Temperature } \\ \mathbf{u}: & \text { Velocity, } \mathbf{u}=\mathbf{u}\left(u_{x}, u_{r}, u_{\theta}\right) \\ V: & \text { Volume } \\ \alpha, & \text { Inverse Prandtl number for } k \text { and } \varepsilon, \\ \delta: & \text { respectively } \\ \varepsilon: & \text { Flow gap } \\ \lambda: & \text { Dissipation rate of turbulence energy } \\ \eta: & \text { Thermal conductivity } \\ \mu: & \text { Ratio of actual open area to total flow area } \\ \rho: & \text { Viscosity } \\ \omega: & \text { Density } \\ \zeta: & \text { Rotational speed }\end{array}$

\section{SUBSCRIPTS}

a: Actual component

eff: Effective

$i, j$ : Tensor notation

max: Maximum

min: Minimum

p: $\quad$ Porous zone

$t$ : Turbulent. 


\section{REFERENCES}

[1] K. R. Weeber and R. N. Dawson, "Reverse flow stator ventilation system for superconducting synchronous machine," US Patent no. 6,703,729, 2004.

[2] W. Tong and C. L. Vandervort, "Optimization of ventilating flow path air gap in reverse flow generators," US Patent no. $6,346,755,2002$.

[3] J. J. Gibney III, "GE generators-an overview," in Proceedings of the 35th GE Turbine State-of-the-Art Technology Seminar, vol. 27, pp. 1-14, Schenectady, NY, USA, August 1991.

[4] V. Yakhot and S. A. Orszag, "Renormalization group analysis of turbulence. I. Basic theory," Journal of Scientific Computing, vol. 1, no. 1, pp. 3-51, 1986.

[5] A. Yakhot, S. A. Orszag, V. Yakhot, and M. Israeli, "Renormalization group formulation of large-eddy simulations," Journal of Scientific Computing, vol. 4, no. 2, pp. 139-158, 1989.

[6] V. Yakhot, S. A. Orszag, S. Thangam, T. B. Gatski, and C. G. Speziale, "Development of turbulence models for shear flows by a double expansion technique," Physics of Fluids A, vol. 4, no. 7, pp. 1510-1520, 1992.

[7] FLUENT Inc., "FLUENT 5-User’s Guide," vol. 2, Lebanon, $\mathrm{NH}, 1998$.

[8] W. Tong, "Numerical investigation of flow field at the rotorstator gap entrance," in Proceedings of the ASME International Mechanical Engineering Congress and Exposition, vol. 250, pp. 39-45, Nashville, Tenn, USA, November 1999.

[9] W. Tong, "Numerical analysis of rotating pumping flows in inter-coil rotor cavities and short cooling grooves of a generator," International Journal of Rotating Machinery, vol. 7, no. 2, pp. 131-141, 2001.

[10] A. K. Sleiti, "Advanced cooling technology for rotors of high-power low-duty cycle generators using polyalphaolefins," Journal of Synthetic Lubrication, vol. 24, no. 2, pp. 77-90, 2007.

[11] R. M. Barron and A. A. S. Neyshabouri, "Effects of underrelaxation factors on turbulent flow simulations," International Journal for Numerical Methods in Fluids, vol. 42, no. 8, pp. 923-928, 2003.

[12] FLUENT Inc., "Porous Media Modeling, Fluent 4.4 User's Guide,” vol. 1, pp. 6-159, 6-186, 1997.

[13] W. Tong and C. L. Vandervort, "Spline retaining ring," US Patent no. 6,285,110, 2001.

[14] W. Tong, C. L. Vandervort, and W. H. Boardman, "Ventilate series loop blocks and associated tie methods," US Patent no. 6,462,458, 2002.

[15] W. Tong, "Adjustable space block baffle for generator and method for controlling ventilation flow," US Patent no. 6,504,273, 2003. 

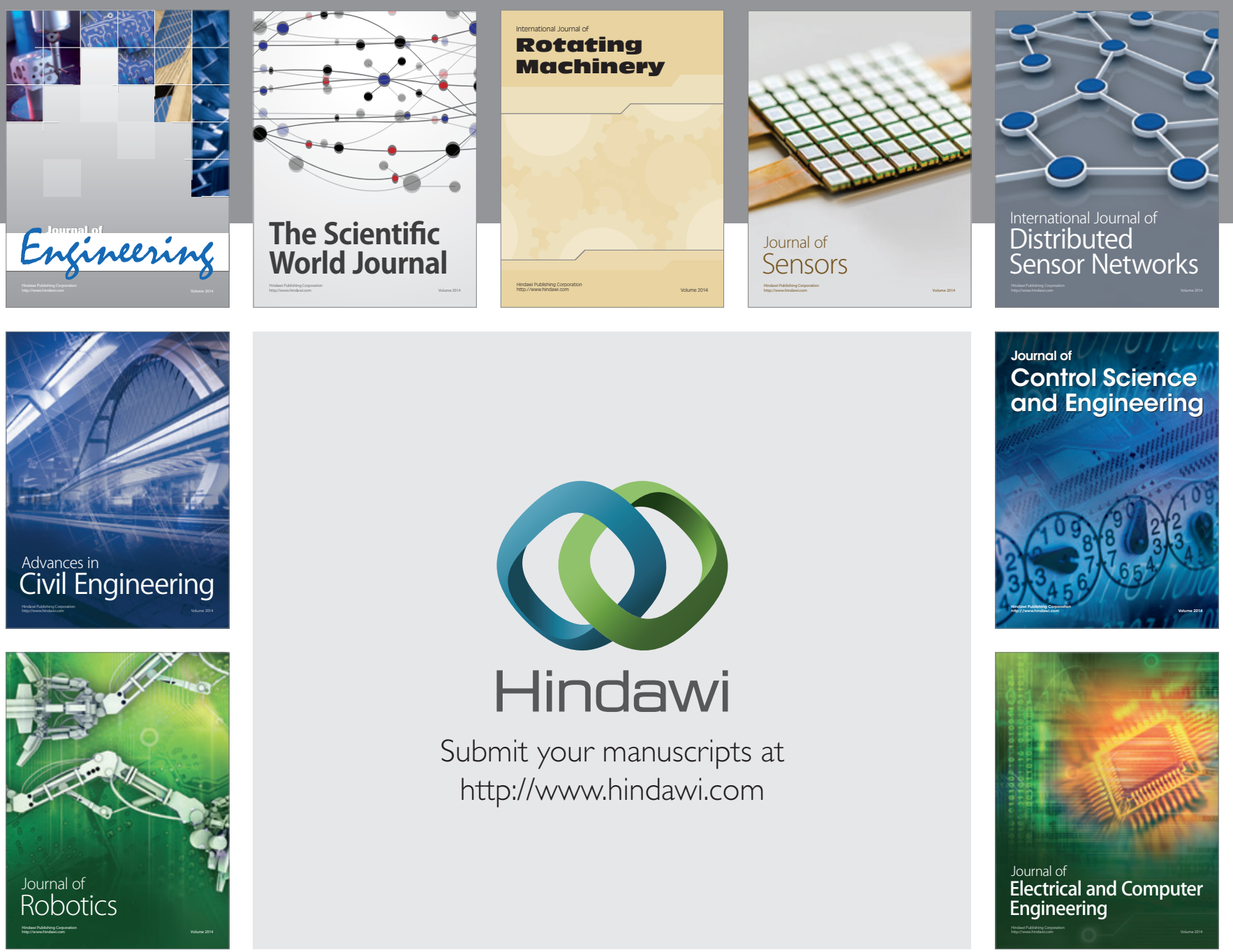

Submit your manuscripts at

http://www.hindawi.com
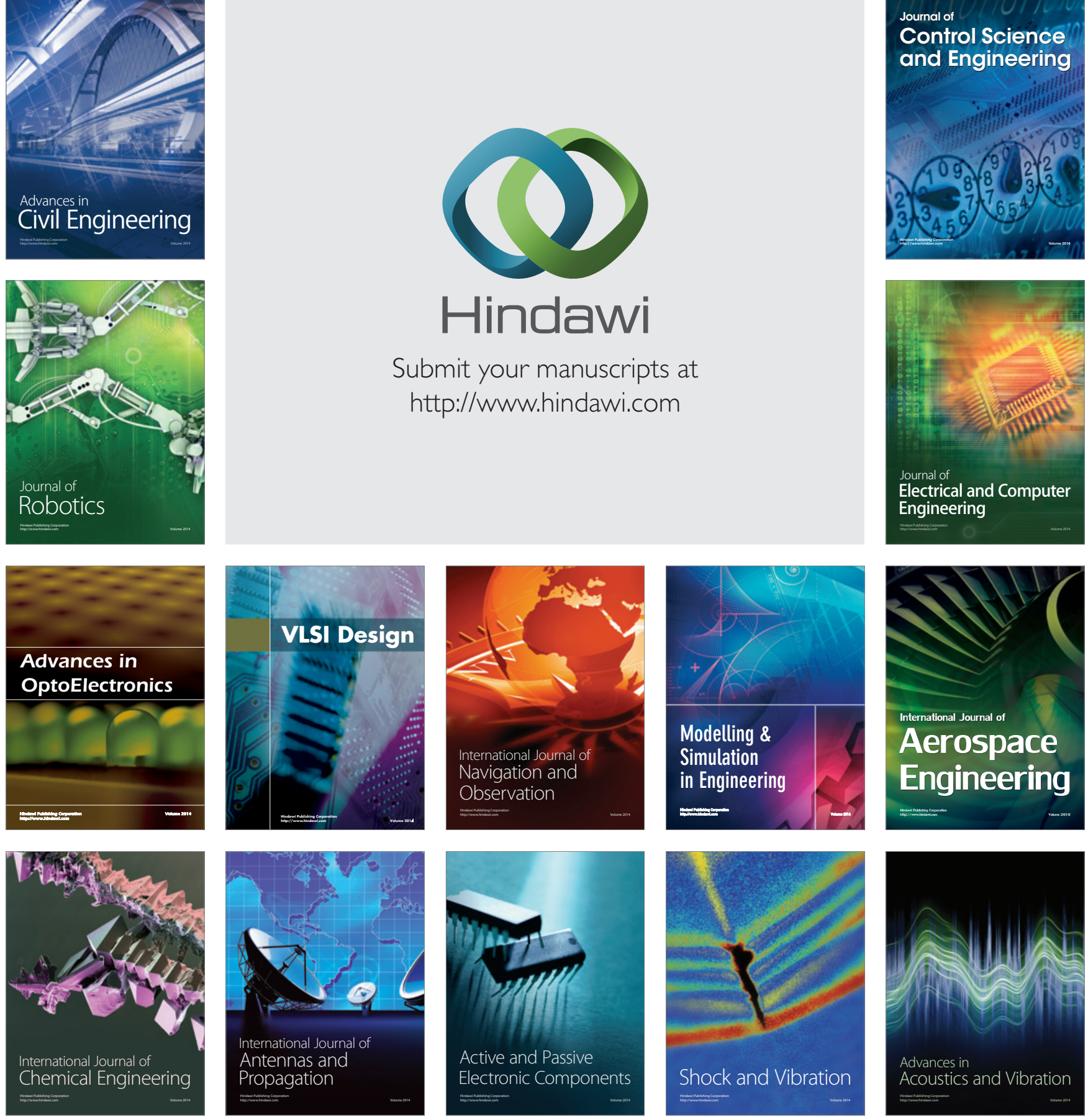